$10-2015$

\title{
State Education Agencies and the Implementation of New Teacher Evaluation Systems
}

Patrick McGuinn

Follow this and additional works at: https://repository.upenn.edu/cpre_policybriefs

Part of the Educational Assessment, Evaluation, and Research Commons, and the Educational Methods Commons

\section{Recommended Citation}

McGuinn, Patrick. (2015). State Education Agencies and the Implementation of New Teacher Evaluation Systems. CPRE Policy Briefs.

Retrieved from https://repository.upenn.edu/cpre_policybriefs/44

View on the CPRE website.

This paper is posted at ScholarlyCommons. https://repository.upenn.edu/cpre_policybriefs/44

For more information, please contact repository@pobox.upenn.edu. 


\title{
State Education Agencies and the Implementation of New Teacher Evaluation Systems
}

\author{
Abstract \\ It has been three years since Race to the Top grant-winning states piloted new teacher evaluation \\ systems and many of them have made considerable progress, yet according to media coverage and a \\ Government Accountability Office report published in April 2015, struggles remain and most grantees \\ have asked to extend the timetables for completing this work. Given the enormous importance and \\ complexity of these reforms - and the fact that states vary widely in the timing, approach, and success of \\ their implementation work - this is an excellent opportunity to assess the progress that has been made \\ and identify where challenges persist. It is imperative that states learn from one another during this \\ implementation stage, and this brief from Patrick McGuinn (Drew University) serves to facilitate the \\ discussion by highlighting what is and is not working in the Race to the Top states.

\section{Disciplines} \\ Educational Assessment, Evaluation, and Research | Educational Methods
}

\section{Comments}

View on the CPRE website. 


\section{GREPolicyBrief}

\section{State Education Agencies and the Implementation of New Teacher Evaluation Systems}

\section{Patrick McGuinn, Drew University}

It has been three years since Race to the Top grant-winning states piloted new teacher evaluation systems and many of them have made considerable progress, yet according to media coverage and a Government Accountability Office [GAO] report published in April 2015, struggles remain and most grantees have asked to extend the timetables for completing this work. Given the enormous importance and complexity of these reforms - and the fact that states vary widely in the timing, approach, and success of their implementation work - this is an excellent opportunity to assess the progress that has been made and identify where challenges persist. It is imperative that states learn from one another during this implementation stage, and this brief serves to facilitate the discussion by highlighting what is and is not working in the Race to the Top states.

\section{FINDINGS}

States have made progress in setting up data systems, designing new observational rubrics, and training and certifying evaluators of teacher practice. However, more work remains to be done around incorporating measures of student achievement into evaluations, particularly for teachers in non-tested subjects and grades. States are also struggling with how to adapt professional development to the new evaluation process.

Confounding these struggles are the challenges that states are facing trying to achieve meaningful differentiation in teacher ratings. Tennessee, Rhode Island, Florida, Indiana, and Michigan all rated more than $95 \%$ of their teachers as effective or highly effective during the 2013-2014 school year. The positive potential of these new evaluations systems is unlikely to be tapped, however, unless evaluators use them to meaningfully differentiate teachers on the quality of their instruction. Having accurate performance data for teachers has many implications across the human capital continuum from staffing decisions, to differentiated pay plans, to promotion into teacher leadership roles and providing professional development.

\section{It is imperative that states learn from one another during this stage.}

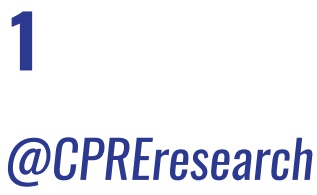

cpre.org 


\section{State Education Agencies and the - Implementation of New Teacher Evaluation Systems}

A common refrain from the field is the need to set realistic expectations around the new teacher evaluation systems-both in the sense that people realize that it is complicated, difficult work during which mistakes will be made and also that getting the new systems operating smoothly and effectively will take several years. It is also important for state education agencies (SEAs) to communicate that these new systems are not primarily intended to be punitive for teachers but rather to improve professional development and classroom instruction.

The next-and crucial-step in the development of these evaluation systems will be maximizing the educational benefit of all of this new information. States have acknowledged the importance of communication and messaging around the new evaluation systems to ensure that the potential benefits are widely understood.

\section{IMPLICATIONS FOR POLICYMAKERS Reallocate SEA resources for discrete functions and regional support.}

Given limited resources, state leaders have to think about how to reallocate existing SEA staff and budgets to focus on new responsibilities, build capacity, and bring work that is funded by external grants on-budget. As they do so, they should consider comparative advantage and economies of scale-where the state can provide something that districts cannot, such as:

- Providing technical assistance and policy interpretation

- Creating networks for information sharing

- Expanding assessment portfolios

- Establishing online training modules

States should reorganize their education agencies (as Tennessee and New Jersey have) around discrete functions rather than funding streams. And they should create human capital offices that can integrate the recruitment, training, evaluation, professional development and recognition of teachers. Given the distance-literal and figurativebetween SEAs and local education agencies (LEAs), it is important to create structuressuch as New Jersey's county offices and regional achievement centers and Pennsylvania's intermediate units-to provide differentiated and targeted support on a regional basis.

\section{Align teacher evaluations with new assessments.}

Implementing new teacher evaluation systems is a major undertaking in its own right, but most states and districts are simultaneously rolling out the new academic standards and aligned assessments. This further strains SEA and LEA capacity and emphasizes the need to think carefully about the sequencing of rollouts of new evaluation systems with interconnected reforms.

There is a crucial role here for states as they set policy; it is imperative that core education policies are well-aligned and stable over time. Teachers and administrators in the field can become disillusioned when major policies become disjointed or unexpectedly changed 
in the middle of being implemented. Tennessee, for example, announced that it would not implement the PARCC assessments at the end of the 2014-15 school year as planned but that it would continue to implement the Common Core State Standards. The state's standards and assessments are therefore misaligned, and educators believe they cannot be fairly evaluated on the new standards with old tests.

\section{Align educator evaluation systems.}

Educators have long complained about the silos in their SEAs and district central offices and their isolation from the field. Given the interconnectedness of teacher evaluations with standards, assessment, and curriculum, state boards of education and administrators in SEAs and LEAs must ensure that these different areas are aligned. Principal evaluation system must be aligned with the new teacher evaluation system to ensure that principals are rewarded for giving priority to assessing and coaching teachers with rigor and objectivity. Pennsylvania, for example, introduced the new Framework for Leadership a year after it launched the new teacher evaluation system. Tennessee also redesigned its principal evaluation system to better align with teacher evaluation.

In a Colorado program, 13 "integration districts" assign teacher leaders as "integration liaisons" to implement new evaluations using a systems-thinking approach that integrates new academic standards, assessment, and evaluations. With the help of their SEA, the district leaders met at several professional development gatherings during the year.

\section{Support principals in evaluation efforts.}

States need to think long-term about how to produce a large and stable supply of SEA staff, principals, and superintendents with the training, technical expertise, and field experience to handle teacher evaluation reform. Partnering with a state's higher education system or management consultants to devise training and certification programs that reflect the required skill sets is crucial. As the primary evaluators, school principals will in large measure determine whether these new evaluation systems succeed. However, it is a major challenge to find time to do meaningful and more numerous evaluations, to conference with teachers about the results of the observations, and to find ways to use the observations to modify and improve instruction.

Some states have tried to redefine the principal's role, reallocating some of their current responsibilities or providing external capacity to help them. One such example is the Pennsylvania Inspired Leadership (PIL) Program, a statewide, standards-based continuing professional education program for school and system leaders that focuses more than traditional programs on evaluation skills and using evaluation data to improving instruction. Some districts in Rhode Island have created collective bargaining agreements whereby teacher leaders can help with the observations. Colorado has established a process whereby a non- 
State Education

Agencies and the -

Implementation

of New Teacher

Evaluation Systems

principal can be trained as an approved evaluation provider.

\section{Provide evaluator training and certification.}

The Rhode Island Department of Education has developed a promising approach to providing ongoing evaluator training. Every summer it runs institutes for all evaluators: a two-day session for veteran principals and a more comprehensive four-day session for new principals and those who are new to an evaluation role. It also offers "calibration sessions" during the academic year in which a team from the department works with a district's leadership team. The sessions focus on setting student learning objectives [SLOs], observing teachers, providing feedback, and scoring learning objectives. Evaluators pass a certification test and annual recertification tests-as they do in Tennessee-to demonstrate their readiness to conduct high-quality observations and ensure inter-rater reliability.

In addition to training and certification for evaluators on the front end, it is also important for state boards, SEAs, and LEAs to monitor results on the back end: Are evaluators achieving a meaningful distribution of observational scores? How well do those scores align with student achievement data? Tennessee's SEA analyzes the data to identify schools that have a pattern of misalignment and offers them optional support in the form of a coach from the SEA.

\section{Use evaluation to facilitate coaching.}

Once new evaluation systems are operational, states need to ensure that the new information they provide drives instructional improvement. For evaluations to inform classroom instruction, teachers need differentiated, targeted professional development that can accommodate the wide range of academic disciplines, grade levels, student demographics, and instructional specialists (i.e., for English as a second language and special education]. Supporting teachers and principals through coaching to use datafrom student assessments and their own evaluations - schools will be better able to create targeted interventions that can drive improvement in student achievement. Creating professional learning communities among groups of educators working in the same subject and/or grade level can be very helpful, as can providing principals with professional development or coaches to assist them in understanding how to analyze and use the new data.

\section{Create a clearinghouse of Student Learning Objectives.}

Because most teachers work in untested grades or subjects, figuring out how to measure student achievement or growth in their classrooms remains perhaps the biggest problem confronting the new teacher evaluation systems. SEAs can play a productive role in identifying and designing assessments that are aligned with state learning standards. In Tennessee, for example, the department of education developed alternative growth measures that are optional for districts to use in non-tested subjects and grades such as in 
world languages, physical education, health, fine arts, special education, and pre- $\mathrm{K}$ and kindergarten.

However, states vary widely in the extent to which they have created sample SLOs, aligned measures and centralized the assessment process for LEAs. Pennsylvania piloted a voluntary SLO process for districts in 2013-14 that was mandated in 2014-15. The Pennsylvania Department of Education worked with an expert to design training, resources, and templates. Pennsylvania then trained their trainers and piloted the system. The state vetted the models that came from the pilot and provided the exemplars and supporting resources to districts free-of-charge in 2014-15.

\section{Centralize data collection and reporting.}

Data collection and reporting systems are a crucial piece of infrastructure for the new evaluations. Districts and states need such systems in order to gather, analyze, and disseminate information about teacher performance: observations, student surveys, and student growth scores. This is where scale is helpful, and statewide solutions will be more efficient and reliable than each district reinventing the wheel. Rhode Island, for example, used its Race to the Top funds to develop the Educator Performance and Support System [EPSS], a platform that helps districts schedule evaluations and collect data and provides evaluators data at individual and aggregate levels. Colorado also built a management performance platform to help districts manage data from their evaluations.

\section{Engage stakeholders.}

SEAs also must be accessible to teachers and principals and answer their technical questions promptly. SEAs need to actively engage district and local education stakeholders in building, piloting, and refining the new evaluation systems. By piloting the new teacher evaluation systems in advance of "going live" statewide, implementers have been able to identify and resolve problems that emerged and give teachers and principals time to adjust to the new system and their roles within it.

Such engagement will produce a better system and also give stakeholders ownership and buy-in in the system. New Jersey's Evaluation Pilot Advisory Committee and the evaluation advisory committees in each district appear to have been effective in this regard. Operating as they do at the top of the state education governance structure, State boards of education (SBEs) have an important role to play in communicating with parents and teachers about what the teacher evaluation changes mean and why they are necessary. These concerns underscore the need for effective lines of communication-horizontally and vertically.

5 


\section{State Education Agencies and the Implementation of New Teacher Evaluation Systems}

\section{GOING FORWARD}

Improving teacher quality has become the centerpiece of the Obama administration's education agenda and of the contemporary school reform movement. The past few years have highlighted how difficult this work is and how short timelines and limited SEA staff, funding, and capacity complicate it further. In particular, states are struggling with the incorporation of student test scores into teacher ratings, how to measure student growth for teachers in non-tested grades and subjects, adapting professional development to the new evaluation process, and achieving meaningful differentiation in teacher ratings. It is important to recognize that the early adopter states discussed here are not a random or representative sample of states. By choosing to apply for a Race to the Top grant, they both self-selected into doing teacher evaluation reform and (because they won] demonstrated a greater initial ability to deliver on it compared with other states. As a result, states that subsequently undertake this work may well struggle even more than these six. But other states can benefit from a close study of the challenges the early adopters encountered in reforming teacher evaluations and how they responded to those challenges, and this analysis can inform their efforts going forward.

\section{WANT MORE INFO?}

This policy brief is based on the printed version that appeared in the September 2015 issue of the National Association of State Boards of Education journal, The State Education Standard [see McGuinn, P. (2015, Sept.]. Remaking teacher evaluation: A heavy lift for state education policymakers. The State Education Standard: Journal of the National Association of State Boards of Education, 15[3), 26-31].

Author Patrick McGuinn also produced a white paper expanding on the research findings and policy implications presented in the aforementioned briefs. See McGuinn, P. (2015). Evaluating progress: State Education Agencies and the implementation of new teacher evaluation systems. White Paper \#2015-09. Philadelphia: Consortium for Policy Research in Education available at cpre.org/teachereval2015.

The opinions expressed in both the policy brief and white paper are those of the author and do not necessarily represent the views of CPRE or its institutional partners.

Contact Patrick McGuinn at pmcguinn@drew.edu.

The Consortium for Policy Research in Education (CPRE) brings together education experts from renowned research institutions to contribute new knowledge that informs PreK-20 education policy and practice. Our work is peer-reviewed and open-access. Visit cpre.org or subscribe to Insights, CPRE's monthly e-newsletter. 